\title{
Epigenetic Therapy for Breast Cancer
}

\author{
Feng-Feng Cai ${ }^{1}$, Corina Kohler ${ }^{1}$, Bei Zhang ${ }^{1}$, Ming-Hong Wang ${ }^{2}$, Wei-Jie Chen ${ }^{1}$ \\ and Xiao-Yan Zhong ${ }^{1, *}$
}

1 Laboratory for Gynecological Oncology, Department of Biomedicine, Women's Hospital, University of Basel, Hebelstrasse 20, Room 420, Basel, CH 4031, Switzerland;

E-Mails: fcai@uhbs.ch (F.-F.C.); kohlerc@uhbs.ch (C.K.); zhangb@uhbs.ch (B.Z.); wchen@uhbs.ch (W.-J.C.)

2 Department of General Practice Medicine, Zhongda Hospital of Southeast University, Nanjing 210009, Jiangsu, China; E-Mail: wangminghong@medmail.com.cn

* Author to whom correspondence should be addressed; E-Mail: zhongx@ @uhbs.ch;

Tel.: +41-612-659-248; Fax: +41-612-659-399.

Received: 20 May 2011; in revised form: 30 June 2011 / Accepted: 1 July 2011 /

Published: 11 July 2011

\begin{abstract}
Both genetic and epigenetic alterations can control the progression of cancer. Genetic alterations are impossible to reverse, while epigenetic alterations are reversible. This advantage suggests that epigenetic modifications should be preferred in therapy applications. DNA methyltransferases and histone deacetylases have become the primary targets for studies in epigenetic therapy. Some DNA methylation inhibitors and histone deacetylation inhibitors are approved by the US Food and Drug Administration as anti-cancer drugs. Therefore, the uses of epigenetic targets are believed to have great potential as a lasting favorable approach in treating breast cancer.
\end{abstract}

Keywords: breast cancer; epigenetic therapy; DNA methylation inhibitors; Histone deacetylation inhibitors

\section{Introduction}

Breast cancer is one of the most common cancers among women [1]. Although early detection and improved treatment have increased breast cancer survival rates during the last decade, the 10 year survival rate is still about $80 \%$ [2]. This shows that there is still need for developing novel therapeutic strategies. 
Genetic and epigenetic alterations have both been shown to play an important role in a variety of cellular processes which include chromatin remodeling, imprinting, $\mathrm{X}$ chromosome inactivation, and carcinogenesis [3]. The most common types of epigenetic alterations include DNA methylation and histone modifications. Unlike genetic mutations, epigenetic changes are reversible making them a more promising and safer alternative in breast cancer therapy.

The treatments of breast cancer demand multidisciplinary therapies. The state-of-the-art treatment options usually include a combination of surgery therapy, radiation therapy, cytotoxic chemotherapy, and molecularly targeted endocrine therapy depending on the type of breast cancer diagnosed [4]. During recent years, a lot of effort has been put into improving targeted therapy, in particular the following two therapies: trastuzumab (Herceptin), directed against the human epidermal growth factor receptor 2 (HER2); and bevacizumab, directed against vascular endothelial growth factor (VEGF). Both targeted therapies have been approved as milestones [5].

Recently, new treatment strategies focusing on epigenetic alterations have been suggested over gene mutation because of reversibility. The establishment and maintenance of epigenetic modifications rely on the operations of special enzymes, DNA methyltransferases and histone deacetylases, which have become the primary targets for epigenetic therapy [6,7]. Epigenetic therapies using the inhibitors of these enzymes have anti-tumorigenic effects on malignant conditions [8]. Therefore, this review will mainly focus on DNA methylation inhibitors and histone deacetylation inhibitors evaluating their potential for future application in epigenetic therapy.

\section{DNA Methylation Inhibitors (DNMT Inhibitors)}

DNA methylation in regulatory regions of genes has been shown to influence gene expression. 5-hydroxymethylcytosine (5hmC), a novel DNA modification in mammalian genomic DNA, can lead to demethylation of DNA and may contribute to the dynamics of DNA methylation $[9,10]$. Hypermethylation at $\mathrm{GpG}$ islands has been linked to transcriptional inactivation of genes. In cancer, these instances of hypermethylation often can be found in genes' promoter regions, which are involved in cell cycle regulation, apoptosis, DNA repair, and informally known as tumor suppressor genes. DNA hypermethylations at $\mathrm{CpG}$ islands have been found in a variety of malignancies including acute myelogenous leukemia (AML), myelodysplastic syndrome (MDS) and other malignancies [11,12].

DNA methylation patterns are established and maintained by a family of enzymes called DNA methyltransferases [13]. During the methylation process, these enzymes catalyze the transfer of a methyl group to the 5 position of cytosin. In mammals, there are three active human DNA methyltransferases, DNMT1, DNMT3A, and DNMT3B. DNMT1 has importance in post-replicative maintenance of DNA methylation patterns in mammalian cells. DNMT3A and DNMT3B, two closely related enzymes, are considered to play a critical role in the de novo establishment of methylation patterns [14]. DNA demethylation can be achieved either by the failure of maintenance methylation after DNA replication, or by replication-independent processes involving base excision repair (BER) and nucleotide excision repair (NER) [15,16]. Tahiliani et al. suggested that the enzyme TET1, an iron-dependent a-ketoglutarate dioxygenase, may be responsible for the conversion of 5-methylcytosine $(5 \mathrm{mC})$ to 5-hydroxymethylcytosine $(5 \mathrm{hmC})$. It provided potential possibilities for demethylation [9]. 
Recent drug developments mainly focus on DNMT inhibitors (DNMTi) including nucleoside analogues and non-nucleoside analogues. By inhibiting DNMTs, genes that might have been silenced by DNA methylation in the course of the carcinogenic process could be reactivated, and the non-carcinogenic status of the cell could be reconstituted. The advantages of DNMT inhibitors are that they are not cancer type specific and could be used to treat various cancers [17].

\subsection{Nucleoside Analogues}

Nucleosides analogues are inhibitors of DNA synthesis and imputed in direct or indirect regulation of DNA methylation [18]. The mechanism of action in nucleoside analogues is based on their transformation to nucleotides and their subsequent incorporation into DNA. The formation of covalent complexes with DNMTs results in enzyme depletion and finally, a reversal of the methylation pattern [19]. There are four well-characterized nucleoside analogue methylation inhibitors, 5-azacytidine, 5-aza-2'-deoxycytidine (5-Aza-CdR), 5'-fluoro-2'-deoxycytidine and Zebularine.

\subsubsection{5-Azacytidine}

5-azacytidine (5-Aza-CR; Vidaza; azacitidine), a global DNMTi, was approved by FDA for the treatment of myelodysplastic syndrome (MDS). The clinical trials that use this product against different solid tumors have been carried out [20]. Azacitidine has two mechanisms of antineoplastic action - cytotoxicity and DNA demethylation [21]. It can be incorporated into both DNA and RNA. 5-Aza-CR treatment of mammalian cells also leads to defective tRNAs and rRNAs, and inhibits protein synthesis [22]. It is considered to cause chromosomal rearrangements and contribute to cytotoxicity [23].

\subsubsection{5'-Aza-2'-Deoxycytidine}

5'-aza-2'-deoxycytidine (5-azaCdR; DAC; decitabine), a cytosine analogue, is also incorporated into DNA during replication. 5'-aza-2'-deoxycytidine inhibits both DNMT1 and DNMT3B. It also leads to enhanced acetylation of histones $\mathrm{H} 3$ and $\mathrm{H} 4$ at the promoter regions. The use of the activating histone mark dimethylated lysine 4 of $\mathrm{H} 3$ was found to be enhanced by DAC by modulating gene expression [24]. 5'-aza-2'-deoxycytidine activates both silenced tumor suppressor genes and pro-metastatic genes by demethylation [20]. PDZ-LIM domain-containing protein 2 (PDLIM2) contains a tumor suppression function and has been shown to be repressed in breast cancer cells. The treatment of breast cancer cells with 5-aza-2'-deoxycytidine reversed the methylation of the PDLIM2 promoter, restored PDLIM2 expression, and suppressed tumorigenicity of human breast cancer cells [25].

5-aza-CdR induces tumor necrosis factor-related apoptosis-inducing ligand (TRAIL) in human breast cancer MDA-231 cells [26]. 5-aza-CdR is pivotal in enhancing chemosensitivity of breast cancer cells to anticancer agents [27].

\subsubsection{5'-Fluoro-2'-Deoxycytidine}

The nucleoside analogue 5'-fluoro-2'-deoxycytidine (5-F-dC; 5-F-CdR) is being evaluated clinically as a DNA methyltransferase inhibitor. It has an inhibitive effect on the action of the methyl 
transfer reaction [28,29]. However it has a lesser underlying effect as a drug since it leads to potentially toxic products [30].

\subsubsection{Zebularine}

Zebularine is characterized as an inhibitor of cytidine deaminase with antitumor characteristics inhibiting DNA methylation and reactivating silenced genes similarly to 5-aza-CdR. The mechanism of action of zebularine as a DNMTi also requires incorporation into DNA after phosphorylation of zebularine to the diphosphate level and conversion to a deoxynucleotide [31]. It acts through post-transcriptional inhibition of DNMTs, inhibition of methyl CpG binding proteins, and alteration of global histone acetylation status. In contrast to other DNMTi, Zebularine is relatively less toxic to breast cancer cell lines [32]. The ability to manage zebularine with other epigenetic therapeutics with the least additive effect has also been established. Zebularine has antimitogenic and angiostatic activities [33].

\subsection{Non-Nucleoside Analogues}

A few non-nucleoside analogues are known to inhibit DNA methylation and rarely made it to clinical trials but active research in this field will possibly lead to the introduction of more compounds of this class in the near future. Non-nucleoside analogues inhibit DNA methylation by binding directly to the catalytic region of the DNMT without incorporating into DNA [34].

RG108, was first characterized by Brueckner et al. in 2005. They showed that it effectively prevented DNA methyltransferases in vitro in human cell lines. It causes demethylation and reactivation of tumor suppressor genes while not affecting the methylation pattern of centromeric satellite sequences [35]. So far, RG108 has not yet entered clinical trials.

Epigallocatechin-3-gallate (EGCG) is the main polyphenol compound of green tea. Treating cancer cells with micromolar concentrations of EGCG showed reduced DNA methylation and elevated transcription of tumor suppressor genes [36]. EGCG is currently being tested in Phase I trials and will be evaluated in phase II and III trials in the near future [37,38].

Psammaplins are derived from the sponge Psseudoceratina purpurea. They are inhibitors of both DNMTs and HDACs [39]. NVP-LAQ824, a Psammapalin derivative, has shown antitumor activity in preclinical studies [40]. It is currently undergoing Phase I clinical trials for hematologic malignancies.

MG98 is an antisense oligonucleotide which prevents translation of DNMT1 mRNA by hybridizing to the 3' untranslated region of the DNMT1 mRNA. In addition to MG98's great advantage due to its low toxicity, MG98 also demonstrates no antitumor activity in various solid cancers and no dose-related effects in Phase I studies; however, a Phase II study is currently underway [41,42].

The cardiovascular drug, hydralazine, promotes demethylation and tumor suppressor gene transcriptional reactivation. Hydrazine is also most likely to increase the efficacy of current biological or chemotherapeutic treatments [43]. In Phase I clinical trials, the drug has been shown to be well-tolerated and devoid of the common side effects of cytotoxic chemotherapy agents. Zambrano et al. additionally showed up to 52\% demethylation of promoter regions in selected tumor suppressor genes upon treatment with different dose levels of the compound. A phase II clinical study using hydralazine in combination with standard cytotoxic chemotherapy is being planned as proof of 
concept that the reactivation of tumor suppressor genes silenced by DNA methylation increases chemotherapy efficacy in solid tumors [44].

\section{Histone Deacetylation Inhibitors (HDAC Inhibitors)}

Histone deacetylation inhibitors (HDAC inhibitors) inhibit histone deacetylase enzymes leading to the accumulation of acetylation in histones and then changing cellular processes that have become defective in cancerous cells. They have been shown to accumulate hyper-acatetylated histones and inhibit tumors [45]. HDAC inhibitors can be divided into four groups: shortchain fatty acids, hydroxamic acids, cyclic tetrapeptides and benzamides [46]. In humans, there are 11 zinc-dependent HDAC inhibitors. Different classes of HDAC inhibitors are now in clinical development for the treatment of both hematologic and solid tumors. Isoform selective HDAC inhibitors in combination with anti-cancer agents may serve as a future strategy for breast cancer therapy [47].

\subsection{Shortchain Fatty Acids}

Butyrate was the first HDAC inhibitor that was shown to inhibit cell growth and induce apoptosis [48]. Butyrate causes hyperacetylation of H3 and H4. Sodium butyrate can enhance radiosensitivity in MCF-7 breast cancer cell lines and can trigger apoptosis by the induction of caspase-10 expression [49]. Valproic acid (VPA), a well-tolerated antiepileptic drug with anti-tumor effects, is the only clinically available histone deacetylase inhibitor on both estrogen-sensitive and estrogen-insensitive breast cancer cells. VPA is a powerful antiproliferative agent in estrogen-sensitive breast cancer cells, making this drug of clinical interest as a new approach in treating breast cancer. Valproic acid inhibits HDAC activity in vitro and in vivo, and relieves HDAC-dependent transcriptional repression and causes hyperacetylation of histones. It is most likely that the acid achieves this through binding to the catalytic center of HDACs. Valproic acid induces differentiation of carcinoma cells. Tumor growth and metastasis formation have been shown to be significantly reduced in animal experiments [50]. Valproic acid induces proteasomal degradation of HDAC2 by selectively inhibiting the catalytic activity of class I HDACs. It induces ER $\alpha$ mRNA and protein without modifying ER $\beta$ in breast cancer cells. It reprograms the cells to a more differentiated and physiologic phenotype in both ER $\alpha$-positive and ER $\alpha$-negative malignant mammary epithelial cells that can improve the sensitivity to endocrine therapy and chemotherapy in breast cancer patients [51].

\subsection{Hydroxamic Acids}

Hydroxamates are active at micromolar to subnanomolar concentrations. Trichostatin A (TSA) is the first hydroxamic acid HDAC inhibitor identified, and most efficiently alters breast cancer cell viability. TSA, which is derived from Streptomyces, possesses anti-HDAC activity. The effect of TSA on cell proliferation and differentiation can be attributed to the inhibition of HDAC. TSA inhibits growth of ER $\alpha$-positive breast cancer cells in vitro and also inhibits breast tumor growth in vivo. TSA enhances acetylation as well as the stability of the ER $\alpha$ protein and p300 protein; proteins that may contribute to the treatment of human breast cancer [52]. TSA synergizes with the demethylating agent 5 -Aza-CdR in the re-expression of genes silenced in the process of carcinogenesis. Additionally, TSA 
combined with EGCG has been shown to have the synergistic effect of reactivating ER $\alpha$ expression in ER $\alpha$-negative breast cancer cells [53].

Suberoylanilide hydroxamic acid (SAHA) is a small molecule inhibitor of both class I and II HDAC enzymes that inhibits the biological target in vivo, and has antitumor activity in solid and hematological tumors. SAHA has been approved by the FDA for the treatment of cutaneous manifestations of cutaneous T-cell lymphoma in patients [54]. It can be safely administered in a chronic oral treatment. SAHA has been investigated in phase I clinical trials in hematological and non-hematological malignancies. Several phase II studies of SAHA are ongoing in breast and other solid malignancies [55]. SAHA increases the anti-tumor effects of taxol in breast cancer in vitro and in vivo by analyzing the cell cycle and apoptosis. It indicates that the synergistic effects result from enhanced G2/M arrest and apoptosis. It also interferes with apoptotic pathway activities. The co-treatment, SAHA and trastuzumab or docetaxel, induces synergistic cytotoxic effects against breast cancer cells [56].

\subsection{Cyclic Tetrapeptides}

Trapoxin (TPX) has been shown to cause accumulation of highly acetylated core histones in a series of mammalian cell lines [57]. Low concentrations of TPX inhibit deacetylation of acetylated histone molecules irreversibly. TPX has not shown any effects in animal models because of its metabolic instability in vivo and has therefore also not come to clinical use [58]. Trapoxin binds covalently to the histone deacetylase through the epoxide moiety. Trapoxin induces the biological effects on the cell cycle and differentiation. TPX, an inhibitor of the eukaryotic cell cycle and inducer of morphological reversion of transformed cells, inhibits histone deacetylase at nanomolar concentrations.

Depsipeptide (FK228, FR901228), a bicyclic peptide isolated from Chromobacterium violaceum, containing a non-cystine disulfide bridge, increases the expression of lipoplex-delivered genes in cultured tumor cells. Depsipeptide increases the expression of the human p53 gene in metastatic breast cancer cells, but not in adjacent normal cells [59]. It can be safely administered when given as a 4-hour infusion [60]. It also can produce obvious antitumor activity in human cancer patients. Antimitotic depsipeptides are receiving attention in cancer treatment as microtubule-targeted compounds. Tasidotin is a microtubule-targeted derivative of the marine depsipeptide dolastatin-15 and is undergoing clinical evaluation for cancer treatments. It inhibits proliferation of breast cancer cells with an adaptable dosage [61].

The hybrid compound cyclic hydroxamic acid-containing peptide (CHAP) is a unique way to develop isoform-specific HDAC inhibitors. CHAPs inhibit HDAC activity in vivo and affect gene expression. HDAC inhibition by CHAPs corresponds to natural cyclic tetrapeptide antibiotics. HDAC1 is highly sensitive to all CHAPs, much more than HDAC6 [62].

Apicidin[cyclo( $\mathrm{N}$-O-methyl-1-tryptophanyl-1-isoleucinyl-d-pipecolinyl-1-2-amino-8-oxodecanoyl)] is a cyclic tetrapeptide with a potent broad spectrum of anti proliferative activity against various cancer cell lines. It effectively inhibits cell proliferation in ER-positive human breast cancer cells by altering the expression of cell cycle regulator proteins and inducing apoptotic cell death and induces the up-regulation of p53 [63]. The special cell-specific effects of apicidin are associated with ER $\alpha$-mediated transcriptional regulation by the regulation of cell cycle arrest and apoptosis. After apicidin treatment 
in MCF-7 breast cancer cells, the expression of ER $\alpha$ and ER $\beta$ is decreased in a dose-dependent manner. Apicidin treatment obviously increases the levels in acetylated histone $\mathrm{H} 3$ and $\mathrm{H} 4$ in H-ras-transformed human breast epithelial (MCF10A-ras) and non-transformed epithelial (MCF10A) cells. MCF10A-ras cells showed a significantly higher growth rate than MCF10A cells on the anti-proliferative effects [64]. Apicidin also obviously decreases occupation of the first exon of the HSD17B1 gene by Polymerase II shown by chromatin immunoprecipitation analysis. It significantly downregulates the HSD17B1 transcript and protein in adenocarcinoma cells by repression of HSD17B1 gene transcription [65].

\subsection{Benzamides}

MS-27-275, one of the most active benzamide derivatives, causes hyperacetylation of nuclear histones in various tumor cell lines. It changes the cell cycle distribution, decreases the S-phase cells, and increases the G1-phase cells [66]. MS-275 (entinostat), a class I HDAC-selective inhibitor, has been used in clinical trials for cancer patients and is currently used in phase II trials. MS-275 can enhance radiosensitivity [67]. It can inhibit breast cancer tumor growth, angiogenesis, and metastasis. Through the involvement of both cell-extrinsic and cell-intrinsic pathways of apoptosis, MS-275 can sensitize TRAIL (tumor necrosis factor-related apoptosis-inducing ligand)-resistant breast cancer xenografts and can be combined with TRAIL to treat invasive breast cancer. MS-275 causes an accumulation of acetylated histones $\mathrm{H} 3$ and H4 in total cellular chromatin. MS-275 drives invasive breast cancer cells to undergo the reversal of EMT (epithelial-mesenchymal transition). By inducing epithelial cell markers, inhibiting mesenchymal cell markers, and regulating the expression of transcription factors, MS-275 ultimately leads to the suppression of cancer metastasis [68]. The combination of MS-275 with Adriamycin mediated by the transcription factor Sp1 to treat breast cancer cells can significantly increase apoptotic cell death by activation of both death receptor and mitochondrial apoptotic pathways [69].

CI-994(N-acetyl-dinaline), a novel oral histone deacetylase inhibitor, is a substituted benzamide derivative that has significant antitumor activity in vitro and in vivo against a broad spectrum of murine and human tumor models [70]. The mechanism of inhibition by CI-994 is not yet known. It causes accumulation of acetylated histones, although it is not able to inhibit HDAC activity in a direct fashion. CI-994 has been used in several Phase I studies and can be combined with other chemotherapeutic agents [71].

\section{Conclusions}

The use of epigenetic therapy, reversing the changes of DNA methylation and histone acetylation patterns, has large potential in the treatment of breast cancer. The recognition of epigenetics offers new avenues for drug discovery and therapeutics [72]. A synergistic effect of a combined use of DNMT and HDAC inhibitors has been observed. With the development of targeted inhibitors of epigenetic modifications, it provides the use of personalized targeted therapies. However, epigenetic drugs, leading to reactivation of tumor-suppressor genes, are critical to the normal functioning of cells. These drugs can be therapeutically used independently or in conjunction with other therapeutic modalities. The combination of conventional therapy with epigenetic therapy using DNMT inhibitors and HDAC 
inhibitors produces the optimal effect [73]. Currently, there has been little success in treating breast cancer by epigenetic drugs. But the drugs continue to undergo clinical trials despite the successful clinical uses of epigenetic therapies to treat hematological malignancies.

\section{Acknowledgments}

This work was supported by China Scholarship Council (CSC). We are grateful to Matt Ji for proofreading the manuscript. We thank Vivian Kiefer, Zeinab Barekati, Ramin Radpour, and Hongbo Chen for their kind assistances.

\section{References}

1. Jemal, A.; Siegel, R.; Ward, E.; Hao, Y.; Xu, J.; Murray, T.; Thun, M.J. Cancer statistics. Ca-Cancer J. Clin. 2008, 58, 71-96.

2. Kelly, K.M.; Shah, N.; Shedlosky-Shoemaker, R.; Porter, K.; Agnese, D. Living post treatment: Definitions of those with history and no history of cancer. J. Cancer Survivor. 2011, 5, 158-166.

3. Taby, R.; Issa, J.P. Cancer epigenetics. Ca-Cancer J. Clin. 2010, 60, 376-392.

4. Alvarez, R.H. Present and future evolution of advanced breast cancer therapy. Breast Cancer Res. 2010, 12, S1.

5. Alvarez, R.H.; Valero, V.; Hortobagyi, G.N. Emerging targeted therapies for breast cancer. J. Clin. Oncol. 2010, 28, 3366-3379.

6. Esteller, M. Cancer epigenomics: DNA methylomes and histone-modification maps. Nat. Rev. Genet. 2007, 8, 286-298.

7. Handel, A.E.; Ebers, G.C.; Ramagopalan, S.V. Epigenetics: Molecular mechanisms and implications for disease. Trends Mol. Med. 2010, 16, 7-16.

8. Egger, G.; Liang, G.; Aparicio, A.; Jones, P.A. Epigenetics in human disease and prospects for epigenetic therapy. Nature 2004, 429, 457-463.

9. Tahiliani, M.; Koh, K.P.; Shen, Y.; Pastor, W.A.; Bandukwala, H.; Brudno, Y.; Agarwal, S.; Iyer, L.M.; Liu, D.R.; Aravind, L; et al. Conversion of 5-methylcytosine to 5-hydroxymethylcytosine in mammalian DNA by MLL partner TET1. Science 2009, 324, 930-935.

10. Robertson, A.B.; Dahl, J.A.; Vågbø, C.B.; Tripathi, P.; Krokan, H.E.; Klungland, A. A novel method for the efficient and selective identification of 5-hydroxymethylcytosine in genomic DNA. Nucleic Acids Res. 2011, 39, e55.

11. Voso, M.T.; D’Alò, F.; Greco, M.; Fabiani, E.; Criscuolo, M.; Migliara, G.; Pagano, L.; Fianchi, L.; Guidi, F.; Hohaus, S.; et al. Epigenetic changes in therapy-related MDS/AML. Chem. Biol. Interact. 2010, 184, 46-49.

12. Hatziapostolou, M.; Iliopoulos, D. Epigenetic aberrations during oncogenesis. Cell. Mol. Life Sci. 2011, 68, 1681-1702.

13. Bestor, T.H. The DNA methyltransferases of mammals. Hum. Mol. Genet. 2000, 9, 2395-2402.

14. Schaefer, M.; Hagemann, S.; Hanna, K.; Lyko, F. Azacytidine inhibits RNA methylation at DNMT2 target sites in human cancer cell lines. Cancer Res. 2009, 69, 8127-8132.

15. Chen, Z.X.; Riggs, A.D. DNA methylation and demethylation in mammals. J. Biol. Chem. 2011, $286,18347-18353$. 
16. Gehring, M.; Reik, W.; Henikoff, S. DNA demethylation by DNA repair. Trends Genet. 2009, 25, 82-90.

17. Cortez, C.C.; Jones, P.A. Chromatin, cancer and drug therapies. Mutat. Res. 2008, 647, 44-51.

18. Krawczyk, B.; Fabianowska-Majewska, K. Alteration of DNA methylation status in K562 and MCF-7 cancer cell lines by nucleoside analogues. Nucleos. Nucleot. Nucleic Acids 2006, 25, 1029-1032.

19. Szyf, M. Epigenetics, DNA methylation, and chromatin modifying drugs. Annu. Rev. Pharmacol. Toxicol. 2009, 49, 243-263.

20. Chik, F.; Szyf, M. Effects of specific DNMT gene depletion on cancer cell transformation and breast cancer cell invasion; toward selective DNMT inhibitors. Carcinogenesis 2011, 32, 224-232.

21. Mabaera, R.; Greene, M.R.; Richardson, C.A.; Conine, S.J.; Kozul, C.D.; Lowrey, C.H. Neither DNA hypomethylation nor changes in the kinetics of erythroid differentiation explain 5-azacytidine's ability to induce human fetal hemoglobin. Blood 2008, 111, 411-420.

22. Christman, J.K. 5-Azacytidine and 5-aza-2'-deoxycytidine as inhibitors of DNA methylation: Mechanistic studies and their implications for cancer therapy. Oncogene 2002, 21, 5483-5495.

23. Kuo, H.K.; Griffith, J.D.; Kreuzer, K.N. 5-Azacytidine induced methyltransferase-DNA adducts block DNA replication in vivo. Cancer Res. 2007, 67, 8248-8254.

24. Li, Q.; Bartlett, D.L.; Gorry, M.C.; O’Malley, M.E.; Guo, Z.S. Three epigenetic drugs up-regulate homeobox gene Rhox5 in cancer cells through overlapping and distinct molecular mechanisms. Mol. Pharmacol. 2009, 76, 1072-1081.

25. Qu, Z.; Fu, J.; Yan, P.; Hu, J.; Cheng, S.Y.; Xiao, G. Epigenetic repression of PDZ-LIM domain-containing protein 2: Implications for the biology and treatment of breast cancer. J. Biol. Chem. 2010, 285, 11786-11792.

26. Xu, J.; Zhou, J.Y.; Tainsky, M.A.; Wu, G.S. Evidence that tumor necrosis factor-related apoptosis-inducing ligand induction by 5-Aza-2'-deoxycytidine sensitizes human breast cancer cells to adriamycin. Cancer Res. 2007, 67, 1203-1211.

27. Mirza, S.; Sharma, G.; Pandya, P.; Ralhan, R. Demethylating agent 5-aza-2-deoxycytidine enhances susceptibility of breast cancer cells to anticancer agents. Mol. Cell Biochem. 2010, 342, 101-109.

28. Beumer, J.H.; Parise, R.A.; Newman, E.M.; Doroshow, J.H.; Synold, T.W.; Lenz, H.J.; Egorin, M.J. Concentrations of the DNA methyltransferase inhibitor 5-fluoro-2'-deoxycytidine (FdCyd) and its cytotoxic metabolites in plasma of patients treated with FdCyd and tetrahydrouridine (THU). Cancer Chemother. Pharmacol. 2008, 62, 363-368.

29. Gowher, H.; Jeltsch, A. Mechanism of inhibition of DNA methyltransferases by cytidine analogs in cancer therapy. Cancer Biol. Ther. 2004, 3, 1062-1068.

30. Boothman, D.A.; Briggle, T.V.; Greer, S. Exploitation of elevated pyrimidine deaminating enzymes for selective chemotherapy. Pharmacol. Ther. 1989, 42, 65-88.

31. Yoo, C.B.; Valente, R.; Congiatu, C.; Gavazza, F.; Angel, A.; Siddiqui, M.A.; Jones, P.A.; McGuigan, C.; Marquez, V.E. Activation of p16 gene silenced by DNA methylation in cancer cells by phosphoramidate derivatives of 2'-deoxyzebularine. J. Med. Chem. 2008, 51, 7593-7601.

32. Billam, M.; Sobolewski, M.D.; Davidson, N.E. Effects of a novel DNA methyltransferase inhibitor zebularine on human breast cancer cells. Breast Cancer Res. Treat. 2010, 120, 581-592. 
33. Balch, C.; Yan, P.; Craft, T.; Young, S.; Skalnik, D.G.; Huang, T.H.; Nephew, K.P. Antimitogenic and chemosensitizing effects of the methylation inhibitor zebularine in ovarian cancer. Mol. Cancer Ther. 2005, 4, 1505-1514.

34. Schuebel, K.; Baylin, S. In living color: DNA methyltransferase caught in the act. Nat. Methods 2005, 2, 736-738.

35. Brueckner, B.; Boy, R.G.; Siedlecki, P.; Musch, T.; Kliem, H.C.; Zielenkiewicz, P.; Suhai, S.; Wiessler, M.; Lyko, F. Epigenetic reactivation of tumor suppressor genes by a novel small-molecule inhibitor of human DNA methyltransferases. Cancer Res. 2005, 65, 6305-6311.

36. Fang, M.Z.; Wang, Y.; Ai, N.; Hou, Z.; Sun, Y.; Lu, H.; Welsh, W.; Yang, C.S. Tea polyphenol (-)-epigallocatechin-3-gallate inhibits DNA methyltransferase and reactivates methylation-silenced genes in cancer cell lines. Cancer Res. 2003, 63, 7563-7570.

37. Moyers, S.B.; Kumar, N.B. Green tea polyphenols and cancer chemoprevention: Multiple mechanisms and endpoints for phase II trials. Nutr. Rev. 2004, 62, 204-211.

38. Chen, D.; Milacic, V.; Chen, M.S.; Wan, S.B.; Lam, W.H.; Huo, C.; Landis-Piwowar, K.R.; Cui, Q.C.; Wali, A.; Chan, T.H.; et al. Tea polyphenols, their biological effects and potential molecular targets. Histol. Histopathol. 2008, 23, 487-496.

39. Piña, I.C.; Gautschi, J.T.; Wang, G.Y.; Sanders, M.L.; Schmitz, F.J.; France, D.; Cornell-Kennon, S.; Sambucetti, L.C.; Remiszewski, S.W.; Perez, L.B.; et al. Psammaplins from the sponge Pseudoceratina purpurea: Inhibition of both histone deacetylase and DNA methyltransferase. J. Org. Chem. 2003, 68, 3866-3873.

40. Atadja, P.; Gao, L.; Kwon, P.; Trogani, N.; Walker, H.; Hsu, M.; Yeleswarapu, L.; Chandramouli, N.; Perez, L.; Versace, R.; et al. Selective growth inhibition of tumor cells by a novel histone deacetylase inhibitor, NVP-LAQ824. Cancer Res. 2004, 64, 689-695.

41. Davis, A.J.; Gelmon, K.A.; Siu, L.L.; Moore, M.J.; Britten, C.D.; Mistry, N.; Klamut, H.; D'Aloisio, S.; MacLean, M.; Wainman, N.; et al. Phase I and pharmacologic study of the human DNA methyltransferase antisense oligodeoxynucleotide MG98 given as a 21-day continuous infusion every 4 weeks. Invest. New Drugs 2003, 21, 85-97.

42. Stewart, D.J.; Donehower, R.C.; Eisenhauer, E.A.; Wainman, N.; Shah, A.K.; Bonfils, C.; MacLeod, A.R.; Besterman, J.M.; Reid, G.K. A phase I pharmacokinetic and pharmacodynamic study of the DNA methyltransferase 1 inhibitor MG98 administered twice weekly. Annu. Oncol. 2003, 14, 766-774.

43. Segura-Pacheco, B.; Trejo-Becerril, C.; Perez-Cardenas, E.; Taja-Chayeb, L.; Mariscal, I.; Chavez, A.; Acuña, C.; Salazar, A.M.; Lizano, M.; Dueñas-Gonzalez, A. Reactivation of tumor suppressor genes by the cardiovascular drugs hydralazine and procainamide and their potential use in cancer therapy. Clin. Cancer Res. 2003, 9, 1596-1603.

44. Zambrano, P.; Segura-Pacheco, B.; Perez-Cardenas, E.; Cetina, L.; Revilla-Vazquez, A.; Taja-Chayeb, L.; Chavez-Blanco, A.; Angeles, E.; Cabrera, G.; Sandoval, K.; et al. A phase I study of hydralazine to demethylate and reactivate the expression of tumor suppressor genes. BMC Cancer 2005, 5, 44.

45. Marsoni, S.; Damia, G.; Camboni, G. A work in progress: The clinical development of histone deacetylase inhibitors. Epigenetics 2008, 3, 164-171. 
46. Fang, M.H.; Ji, X.M. Histone modification and its application in therapy for hematologic malignancies. Zhongguo Shi Yan Xue Ye Xue Za Zhi 2009, 17, 816-820 (in Chinese).

47. Namdar, M.; Perez, G.; Ngo, L.; Marks, P.A. Selective inhibition of histone deacetylase 6 (HDAC6) induces DNA damage and sensitizes transformed cells to anticancer agents. Proc. Natl. Acad. Sci. USA 2010, 107, 20003-20008.

48. Candido, E.P.; Reeves, R.; Davie, J.R. Sodium butyrate inhibits histone deacetylation in cultured cells. Cell 1978, 14, 105-113.

49. Cho, H.J.; Kim, S.Y.; Kim, K.H.; Kang, W.K.; Kim, J.I.; Oh, S.T.; Kim, J.S.; An, C.H. The combination effect of sodium butyrate and 5-Aza-2'-deoxycytidine on radiosensitivity in RKO colorectal cancer and MCF-7 breast cancer cell lines. World J. Surg. Oncol. 2009, 7, 49:1-49:7.

50. Göttlicher, M.; Minucci, S.; Zhu, P.; Krämer, O.H.; Schimpf, A.; Giavara, S.; Sleeman, J.P.; Coco, F.L.; Nervi, C.; Pelicci, P.G.; et al. Valproic aciddefines a novel class of HDAC inhibitors inducing differentiation of transformed cells. EMBO J. 2001, 20, 6969-6978.

51. Travaglini, L.; Vian, L.; Billi, M.; Grignani, F.; Nervi, C. Epigenetic reprogramming of breast cancer cells by valproic acid occurs regardless of estrogen receptor status. Int. J. Biochem. Cell. Biol. 2009, 41, 225-234.

52. Kim, S.H.; Kang, H.J.; Na, H.; Lee, M.O. Trichostatin A enhances acetylation as well as protein stability of ER $\alpha$ through induction of p300 protein. Breast Cancer Res. 2010, 12, R22.

53. Li, Y.; Yuan, Y.Y.; Meeran, S.M.; Tollefsbol, T.O. Synergistic epigenetic reactivation of estrogen receptor- $\alpha(\mathrm{ER} \alpha)$ by combined green tea polyphenol and histone deacetylase inhibitor in ER $\alpha$-negative breast cancer cells. Mol. Cancer 2010, 9, 274.

54. Stearns, V.; Zhou, Q.; Davidson, N.E. Epigenetic regulation as a new target for breast cancer therapy. Cancer Invest. 2007, 25, 659-665.

55. Xu, W.S.; Perez, G.; Ngo, L.; Gui, C.Y.; Marks, P.A. Induction of polyploidy by histone deacetylase inhibitor: A pathway for antitumor effects. Cancer Res. 2005, 65, 7832-7839.

56. Bali, P.; Pranpat, M.; Swaby, R.; Fiskus, W.; Yamaguchi, H.; Balasis, M.; Rocha, K.; Wang, H.G.; Richon, V.; Bhalla, K. Activity of suberoylanilide hydroxamic acid against human breast cancer cells with amplification of her-2. Clin. Cancer Res. 2005, 11, 6382-6389.

57. Kijima, M.; Yoshida, M.; Sugita, K.; Horinouchi, S.; Beppu, T. Trapoxin, an antitumor cyclic tetrapeptide, is an irreversible inhibitor of mammalian histone deacetylase. J. Biol. Chem. 1993, 268, 22429-22435.

58. Monneret, C. Histone deacetylase inhibitors. Eur. J. Med. Chem. 2005, 40, 1-13.

59. Liu, Y.; Liggitt, D.; Fong, S.; Debs, R.J. Systemic co-administration of depsipeptide selectively targets transfection enhancement to specific tissues and cell types. Gene Ther. 2006, 13, 1724-1730.

60. Marshall, J.L.; Rizvi, N.; Kauh, J.; Dahut, W.; Figuera, M.; Kang, M.H.; Figg, W.D.; Wainer, I.; Chaissang, C.; Li, M.Z.; et al. A phase I trial of depsipeptide (FR901228) in patients with advanced cancer. J. Exp. Ther. Oncol. 2002, 2, 325-332.

61. Ray, A.; Okouneva, T.; Manna, T.; Miller, H.P.; Schmid, S.; Arthaud, L.; Luduena, R.; Jordan, M.A.; Wilson, L. Mechanism of action of the microtubule-targeted antimitotic depsipeptide tasidotin (formerly ILX651) and its major metabolite tasidotin C-carboxylate. Cancer Res. 2007, 67, 3767-3776. 
62. Furumai, R.; Komatsu, Y.; Nishino, N.; Khochbin, S.; Yoshida, M.; Horinouchi, S. Potent histone deacetylase inhibitors built from trichostatin A and cyclic tetrapeptide antibiotics including trapoxin. Proc. Natl. Acad. Sci. USA 2001, 98, 87-92.

63. Im, J.Y.; Park, H.; Kang, K.W.; Choi, W.S.; Kim, H.S. Modulation of cell cycles and apoptosis by apicidin in estrogen receptor (ER)-positive and-negative human breast cancer cells. Chem. Biol. Interact. 2008, 172, 235-244.

64. Park, H.; Im, J.Y.; Kim, J.; Choi, W.S.; Kim, H.S. Effects of apicidin, a histone deacetylase inhibitor, on the regulation of apoptosis in H-ras-transformed breast epithelial cells. Int. J. Mol. Med. 2008, 21, 325-333.

65. Keles, E.; Lianeri, M.; Jagodziński, P.P. Apicidin suppresses transcription of 17 $\beta$-hydroxysteroid dehydrogenase type 1 in endometrial adenocarcinoma cells. Mol. Biol. Rep. 2011, 38, 3355-3360.

66. Saito, A.; Yamashita, T.; Mariko, Y.; Nosaka, Y.; Tsuchiya, K.; Ando, T.; Suzuki, T.; Tsuruo, T.; Nakanishi, O. A synthetic inhibitor of histone deacetylase, MS-27-275, with marked in vivo antitumor activity against human tumors. Proc. Natl. Acad. Sci. USA 2009, 96, 4592-4597.

67. Camphausen, K.; Burgan, W.; Cerra, M.; Oswald, K.A.; Trepel, J.B.; Lee, M.J.; Tofilon, P.J. Enhanced radiation-induced cell killing and prolongation of gammaH2AX foci expression by the histone deacetylase inhibitor MS-275. Cancer Res. 2004, 64, 316-321.

68. Srivastava, R.K.; Kurzrock, R.; Shankar, S. MS-275 sensitizes TRAIL-resistant breast cancer cells, inhibits angiogenesis and metastasis, and reverses epithelial-mesenchymal transition in vivo. Mol. Cancer Ther. 2010, 9, 3254-3266.

69. Xu, J.; Zhou, J.Y.; Wei, W.Z.; Philipsen, S.; Wu, G.S. Sp1-mediated TRAIL induction in chemosensitization. Cancer Res. 2008, 68, 6718-6726.

70. Riva, L.; Blaney, S.M.; Dauser, R.; Nuchtern, J.G.; Durfee, J.; McGuffey, L.; Berg, S.L. Pharmacokinetics and cerebrospinal fluid penetration of CI-994 ( $N$-acetyldinaline) in the nonhuman primate. Clin. Cancer Res. 2000, 6, 994-997.

71. Perabo, F.G.; Müller, S.C. New agents for treatment of advanced transitional cell carcinoma. Annu. Oncol. 2007, 18, 835-843.

72. Kelly, T.K.; De, Carvalho, D.D.; Jones, P.A. Epigenetic modifications as therapeutic targets. Nat. Biotechnol. 2010, 28, 1069-1078.

73. Kristensen, L.S.; Nielsen, H.M.; Hansen, L.L. Epigenetics and cancer treatment. Eur. J. Pharmacol. 2009, 625, 131-142.

(C) 2011 by the authors; licensee MDPI, Basel, Switzerland. This article is an open access article distributed under the terms and conditions of the Creative Commons Attribution license (http://creativecommons.org/licenses/by/3.0/). 